\title{
Fractionation of lignin produced from the Earleaf Acacia tree by the sequential industrial organic solvents
}

\author{
Thong Hoang Le ${ }^{1,2}$, Khanh B. Vu ${ }^{1,2}$, Quynh-Thy Song Nguyen ${ }^{3}$, Phat Van Huynh ${ }^{4}$, Khanh-Ly T. Huynh ${ }^{1,2}$, \\ Khoa Dang Tong ${ }^{1,2}$, Thong Le Minh Pham ${ }^{5,6}$, An Tran Nguyen Minh ${ }^{7}$, Van Cuong Nguyen? \\ Thanh Khoa Phung 1,2,*
}

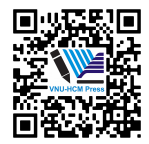

Use your smartphone to scan this QR code and download this article

${ }^{1}$ School of Biotechnology, International University, Ho Chi Minh City, Vietnam ${ }^{2}$ Vietnam National University, Ho Chi Minh City, Vietnam

${ }^{3}$ Industrial Development Center of Southern Vietnam, Ministry of Industry and Trade, 12 Nguyen Thi Minh Khai street, District 1, Ho Chi Minh City Vietnam

${ }^{4}$ Faculty of Chemical Engineering, Ho Chi Minh City University of Food Industry, 140 Le Trong Tan Street, Tay Thanh Ward, Tan Phu District, Ho Chi Minh City, Vietnam.

${ }^{5}$ Institute of Research and Development. Duy Tan University, Da Nang City 550000, Vietnam

${ }^{6}$ Faculty of Environmental and Chemical Engineering, Duy Tan University, Da

Nang, 550000, Vietnam

${ }^{7}$ Faculty of Chemical Engineering Industrial University of Ho Chi Minh City, Ho Chi Minh City, Vietnam, 12 Nguyen Van Bao Road, Ward 4, Go Vap District, Ho Chi Minh City, Vietnam

Correspondence

Thanh Khoa Phung, School of Biotechnology, International University, Ho Chi Minh City, Vietnam

Vietnam National University, Ho Chi Minh City, Vietnam

Email: ptkhoa@hcmiu.edu.vn

History

- Received: 2020-12-31

- Accepted: 2021-02-16

- Published: 2021-02-23

DOI : 10.32508/stdj.v24i1.2509

\section{Check for updates}

\section{Copyright}

(๑) VNU-HCM Press. This is an openaccess article distributed under the terms of the Creative Commons Attribution 4.0 International license.

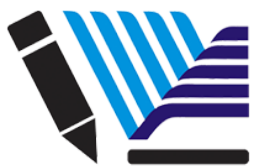

VNU-HCM Press

\begin{abstract}
Introduction: Understanding the properties of the lignin's fractions is important for further conversion of lignin into valuable products. Herein, the "home-made" lignin from the Earleaf Acacia tree was extracted by the sequential industrial organic solvents and characterized the fractions to reveal their properties for further applications. Methods: In this work, lignin was prepared from the Earleaf Acacia tree using the soda method. Then, the prepared lignin was fractionated by the sequential solvents of ethyl acetate, ethanol, methanol, and acetone. The lignin's fractions were characterized by FT-IR and GPC. Results: The FT-IR results confirmed lignin could be produced from woodchips by the soda method. The fractionation of lignin separated the lignin mixture into different molecular weight fractions from light-medium into heavy compounds. Conclusion: Lignin was produced from woodchips using the soda method successfully. The fractionation using the sequential organic solvents showed the separation of lignin into different molecular weights fractions. Each fraction can be converted into useful products properly.

Key words: Lignin, fractionation, ethyl acetate, ethanol, methanol, acetone
\end{abstract}

\section{INTRODUCTION}

Lignin is the main component of vascular plants, along with cellulose and hemicellulose. Therefore, it has a huge abundant resource on the earth, and it contains ca. $20-30 \%$ of lignocellulosic biomass ${ }^{1}$. Currently, lignin is mainly produced from the pulp and paper industry and is considered a solid waste for burning to produce heat and energy ${ }^{2}$. However, lignin has a high potential application in the industry due to its polymer structure ${ }^{3-5}$ and aromatic backbones ${ }^{6-8}$. Indeed, lignin is a biopolymer with $\mathrm{C}-$ $\mathrm{O}-\mathrm{C}$ and $\mathrm{C}-\mathrm{C}$ linkages of the phenylpropane unit, which contains hydroxyphenyl $(\mathrm{H})$, guaiacyl $(\mathrm{G})$, and syringyl (S) types (Figure 1) ${ }^{9}$.

Due to this structure, lignin can be applied in cement, binders ${ }^{10}$, surfactant ${ }^{11}$, and friendly biopolymer with biodegradability, antioxidants, and UV-protection ${ }^{12}$. In addition, the conversion of aromatic backbones to form aromatic compounds using for many applications, such as automotive brakes, wood panel products, surfactants, phenolic resins, phenolic foams, dispersants, polyurethane foams, and epoxy resins ${ }^{7,13,14}$. In parallel, the demand for green fuels increases due to the development of the industry and the reduction of the dependence on fossil resources. Currently, many studies are focusing on the conversion of lignin model compounds and industrial lignin ${ }^{15-18}$. However, lignin is a complex mixture of many polymers, so that the transformation of "full" lignin is hard to be selective and control the desired products. To make an easy way to convert lignin, lignin is fractionated into different fractions using industrial organic solvents. The conversion of real lignin faced several problems, such as challenging reaction conditions ${ }^{19,20}$ and the fast deactivation of the catalyst due to the ester structures in lignin ${ }^{21}$. Indeed, the conversion of the lignin's fractions is easier than real lignin ${ }^{22}$. Therefore, lignin's fractionation is very interested in recent years ${ }^{23,24}$, in which lignin can be fractionated into different fractions with different molecular weights ${ }^{23-25}$. The lignin's fractions with different molecular weights can be applied for different purposes and transformed into chemicals and fuels with a suitable condition. Hence, the fractionation of a complex mixture of lignin is important for further studies.

To fractionate lignin into different parts, lignin produced from the Earleaf acacia tree, an abundant tree to reforest and use in the pulp and paper industry in Vietnam, is fractionated into different fractions. The solvent extraction has been applied to fractionate according to molecular weight by sequential extraction 
with organic solvents ${ }^{26-30}$. Duval et al. ${ }^{3}$ showed that the trend of the yields of the soluble fraction and average molecular weight and polydispersity of the soluble fraction in the different solvents is acetone $>$ methanol $>$ ethanol > ethyl acetate. Based on that result, this solvent extract sequence is utilized for the prepared lignin. FT-IR and GPC techniques used characterize each fraction to study the structure of the fraction and provide a full picture of the "small" lignin fractions for further conversion of lignin in the next step.

\section{MATERIALS AND METHODS}

\section{Materials}

The Earleaf acacia woodchips were purchased in Bien Hoa City, Dong Nai province then were cut into small pieces with a dimension of $30 \mathrm{~mm}$ x $60 \mathrm{~mm}$. Ethyl acetate (Fisher, 99.8\%), Methanol (Fisher, 99.9\%), Acetone (Fisher, 99.8\%), Ethanol (Fisher, 99.8\%), $\mathrm{NaOH}$ (Fisher, extra pure), $\mathrm{HCl}$ (Fisher, 37\%), and Dimethyl sulfoxide (Fisher, 99.9\%) were used without any pretreatment. Lignosulfonic acid sodium salt (denoted as lignosulfonate) purchased from Sigma-Aldrich was used as a reference of lignin.

\section{Lignin preparation and fractionation}

The Earleaf acacia woodchips were dried at $105^{\circ} \mathrm{C}$ until unchanged weight; the percentage of water in the wood is $11.64 \%$. The dried wood, $\mathrm{NaOH}$, and water were filled into a batch reactor with the ratio of dried wood $/ \mathrm{Na}_{2} \mathrm{O} / \mathrm{H}_{2} \mathrm{O}=500 \mathrm{~g} / 90 \mathrm{~g} / 2500 \mathrm{~mL}$, then processed as described in Figure 2. Firstly, the batch reactor was heated at $100^{\circ} \mathrm{C}$ to reach the pressure of 40 bar, then released the pressure to atmospheric pressure. Next, the system was closed and heated to $160^{\circ} \mathrm{C}$ and hold for $5 \mathrm{~h}$; the pressure at this point was ca. 70 bar. After finishing the pulping process, the system was released the pressure and collected pulp and black liquid. A gel of lignin was formed by neutralizing the black liquid with $\mathrm{HCl} 1 \mathrm{M}$ at $\mathrm{pH}=6 \div 7$. The dried lignin (denoted as lignin_prepared) was collected after freeze-drying lignin gel at $-50^{\circ} \mathrm{C}$ for $12 \mathrm{~h}$, then kept in the dark color bottle and stored in a freeze before using it.

For fractionation, the prepared lignin was sequentially fractionated with ethyl acetate, ethanol, methanol, and acetone as described elsewhere (3). The lignin and specified solvent with a ratio of $1 \mathrm{~g}$ :10 mL of lignin/solvent were added in a $100 \mathrm{~mL}$ beaker. After that, the mixture was agitated for $1 \mathrm{~h}$ using a magnetic stirrer at room temperature. The undissolved material was filtered over a P5 Qualitative filter paper with particle retention of
5-10 $\mu \mathrm{m}$ (Fisher Scientific, Hampton, NH). The solid fraction was dried at $50^{\circ} \mathrm{C}$ for 30 minutes to remove the remaining solvent, and then it was fractionated with a sequential solvent, as illustrated in Figure 3. The undissolved solid after each solvent extraction was denoted as lignin_solvent, such as lignin_EA, lignin_EtOH, lignin_MeOH, and lignin_Ace.

\section{Characterization \\ FT-IR study}

FT-IR spectra of the prepared lignin and fractions were recorded in the air using a Jasco spectrometer equipped with an ATR cell (attenuated total reflectance). The IR spectra were performed with 16 scans, scanning speed of $2 \mathrm{~mm} / \mathrm{s}$ at the resolution of 4 $\mathrm{cm}^{-1}$ and a wavenumber range between $4000 \mathrm{~cm}^{-1}$ to $550 \mathrm{~cm}^{-1}$.

\section{GPC study}

Lignin solutions, $2 \mathrm{mg} / \mathrm{mL}$, were prepared in Dimethyl sulfoxide (DMSO). The polydispersity of dissolved lignin was determined by gel permeation chromatography (GPC) using an Agilent 1100 - GPC with a differential refractive index detector (RID detector). The separation was achieved by a PLgel Mix A column at $40{ }^{\circ} \mathrm{C}$ using DMSO as the mobile phase at a flow rate of $0.5 \mathrm{~mL} / \mathrm{min}$. Polystyrene standards were used for calibration. The GPC measurement used to determine molecular mass using linear polystyrene as the reference material in this study is only valid for the relative molecular mass distribution of lignin extracted with different organic solvents. The molecular mass value of lignin is not considered to be exact.

\section{RESULTS}

\section{Lignin production}

In this work, lignin was produced via the traditional soda process. $\mathrm{HCl}$ neutralized liquid lignin solution to $\mathrm{pH}=6-7$, then freeze-dried to obtain lignin powder. The yield of lignin, in this case, was around 13.54 wt.\%. This yield is not high compared to the lignin content $(20-30 \%)$ in lignocellulosic materials. However, it is in agreement with the previous study proving that lignin's yield strongly depends on the value of $\mathrm{pH}$ treatment [24].

\section{Lignin fractionation}

Lignin was successfully fractionated using four industrial solvents, as showed in Figure 3. The highest yield of dissolved lignin in this process was obtained using ethanol solvent following by ethyl acetate, methanol, 


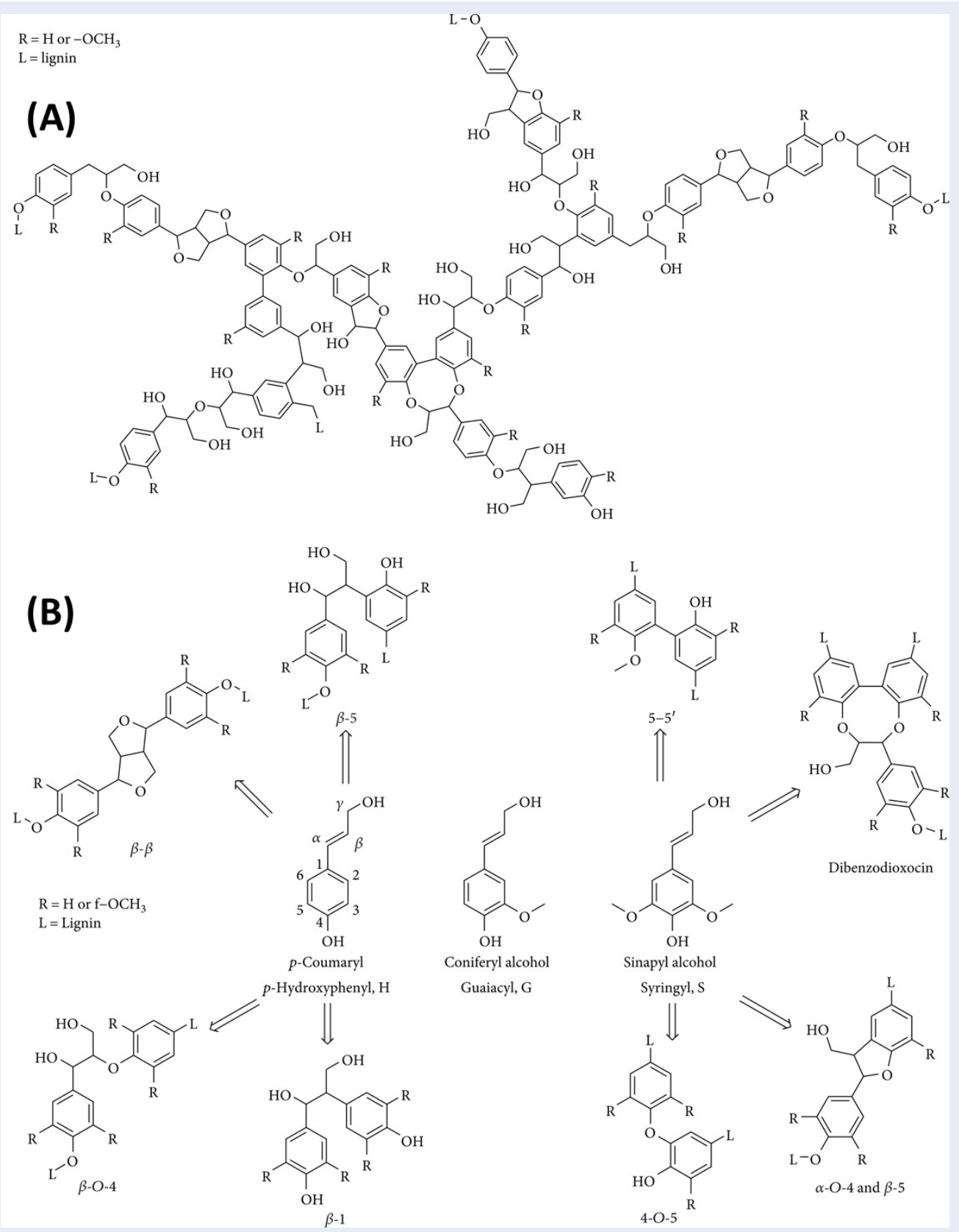

Figure 1: The structure of lignin: (a) A model structure, and (b) the main units and linkages of lignin. Reproduced from Open-access ref. ${ }^{9}$ 


\section{$+\mathrm{NaOH}+\mathrm{H}_{2} \mathrm{O}$}

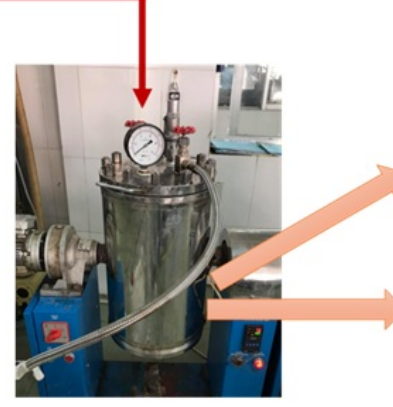

$160^{\circ} \mathrm{C}, 5 \mathrm{~h}$

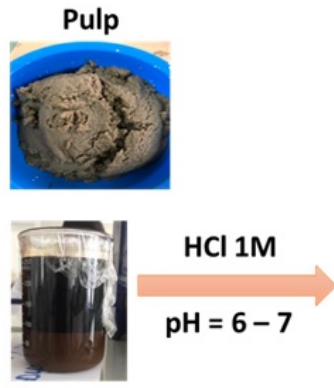

Black liquid

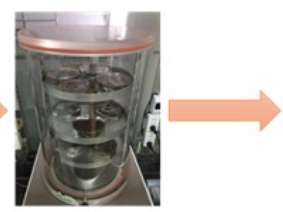

Freeze-drying

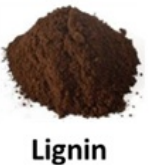

powder

Figure 2: The scheme of lignin production from wood chips of the Earleaf Acacia tree using $\mathrm{NaOH}$ at $160^{\circ} \mathrm{C}$ for $5 \mathrm{~h}$ followed by neutralizing using $\mathrm{HCl} 1 \mathrm{M}$ and freeze-drying at $-50^{\circ} \mathrm{C}$ for $12 \mathrm{~h}$.

$1 \mathrm{~g}$ solid : $10 \mathrm{~mL}$ solvent (1:10 w/v), room temperature, stir for $1 \mathrm{~h}$

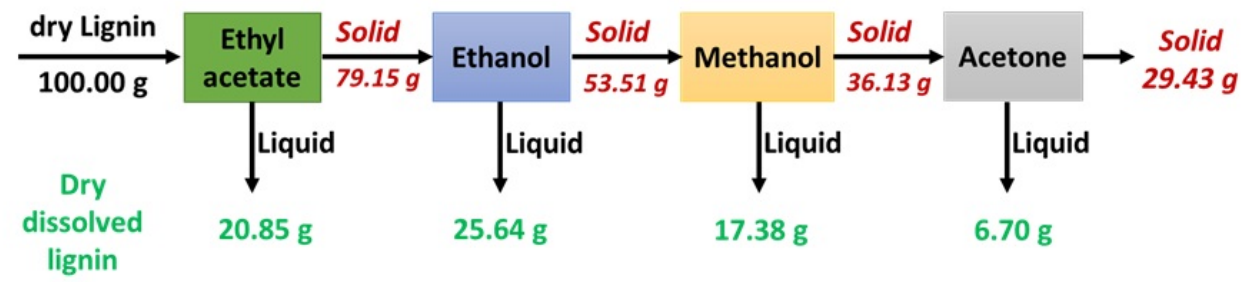

Figure 3: The scheme of fractionation of lignin using the sequential industrial organic solvents of ethyl acetate, ethanol, methanol and acetone with a ratio of solid/solvent $=1 \mathrm{~g} / 10 \mathrm{~mL}$ at room temperature.

and acetone. However, any following step is an accumulation of the previous step. The results also figured out that all four solvents did not dissolve all lignin, and it remained ca. 30\% residue after fractionation process. Only $6.7 \%$ of dissolved lignin was extracted using acetone at the final step due to a high amount of long-chain polymer remaining in the lignin sample. Suggesting that the fractionation process of the prepared lignin can be carried out using three first solvents to fractionated into four fractions (three dissolved lignin fractions and one solid residue) with a high percentage ( $>20 \%$ ) for further conversion of each lignin fraction.

\section{FT-IR study}

It can be seen that Figure 4 showed the typical lignin spectra of the prepared lignin and fractions ${ }^{22,31,32}$. The peaks of the prepared lignin and its fractions are similar to the lignosulfonate. For the prepared lignin and its fractions, the peak at ca. $3370 \mathrm{~cm}^{-1}$ was assigned to $\mathrm{OH}$ stretching, indicating that all lignin samples contain a large number of hydroxyl groups. The peaks at 2923 and $2855 \mathrm{~cm}^{-1}$ were assigned for $-\mathrm{CH}_{3}$ and $-\mathrm{CH}_{2}$ stretching. The absorption peaks in the range of $1560-1404 \mathrm{~cm}^{-1}$ were assigned to the skeletal vibrations and $\mathrm{C}-\mathrm{H}$ deformation combined with aromatic ring vibrations ${ }^{31}$. The peaks at 1345 , 1323,1222 , and $1116 \mathrm{~cm}^{-1}$ indicated that the prepared lignin is mainly composed of G-type and S-type units $^{22}$. In comparison, the absorption peak at 1092 $\mathrm{cm}^{-1}$ corresponded to the deformation vibration of aromatic $\mathrm{C}-\mathrm{H}$ in-plane ${ }^{31}$. Comparing the intensity between the lignin's fractions and the prepared lignin, the peaks of aromatic ring vibrations in the range of $1560-1404 \mathrm{~cm}^{-1}$ decreased the intensity through extraction with a sequence of organic solvents. Also, the 


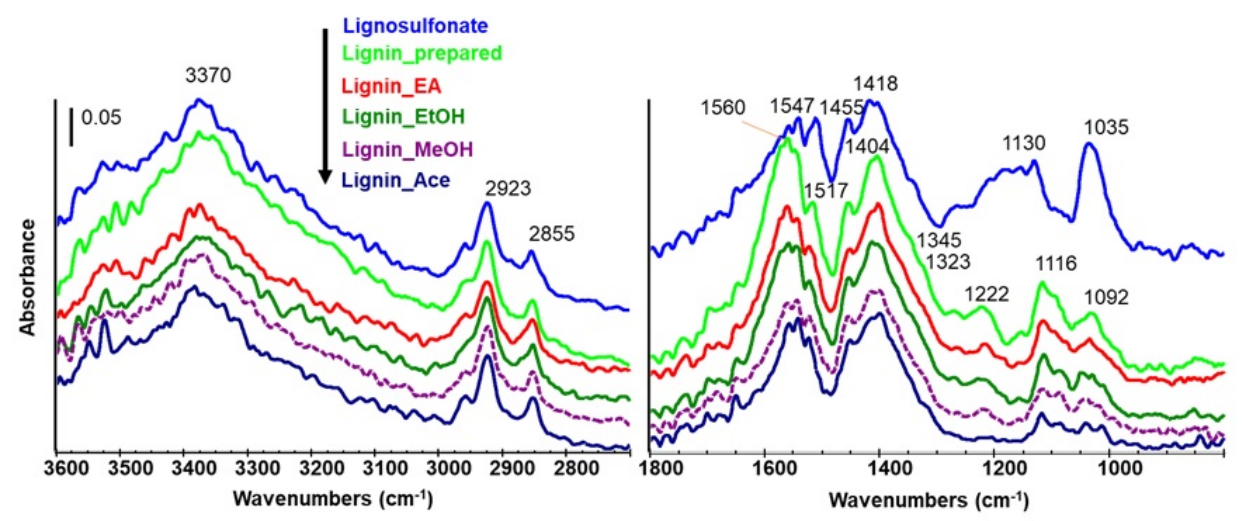

Figure 4: The ATR-FT-IR spectra of the prepared lignin, solid fractions after fractionating using the sequential industrial organic solvents of ethyl acetate, ethanol, methanol and acetone, and a reference, lignosulfonate.

peaks in the range of $1345-1116 \mathrm{~cm}^{-1}$ corresponding to $\mathrm{G}$ type and $\mathrm{S}$ type units decreased the intensity and almost disappeared the peak at $1222 \mathrm{~cm}^{-1}$ in the case solid after fractionating with acetone, suggesting that the sequential organic solvents used extracted different fractions of lignin very well.

\section{GPC study}

The GPC data showed how effective fractionation using industrial solvents. Our data are comparable with the literature ${ }^{19,25,33}$. The prepared lignin showed the long-range distribution of molecular weight (MW) with most low molecular weight (Figure 5). After fractionating using ethyl acetate, the low molecular weight compounds seemed to dissolve into the ethyl acetate solution resulting in the broad curve in $\mathrm{MW}$ from 1000 to $7000 \mathrm{Da}$. The next step with ethanol presented a clear distribution of remained lignin solid with the major medium molecular weight fraction. Besides, the low molecular weight fraction and likely a part of the medium molecular weight fraction were dissolved into ethanol solvent. For the methanol and acetone solvents, molecular weight distribution is almost similar due to the low extraction using acetone. The high molecular weight fractions are dominant in both cases, suggesting that both methanol and acetone dissolve very well the medium and a part of high molecular weight fractions. For acetone solvent, the curve is slightly different from that of methanol. The $6.7 \%$ extracted fraction through acetone changed the shape of molecular weight distribution of the remaining solid lignin, suggesting that methanol and acetone can dissolve a high amount of the medium and high molecular weight fractions.

\section{DISCUSSION}

The ATR-FT-IR spectra confirmed lignin produced from the Earleaf Acacia tree is successful. The IR spectra showed similarities with the lignin from Sigma-Aldrich as a reference. However, the yield is lower than expected, suggesting that the improvement needs to study to enhance the yield of lignin from woodchips.

For the fractionation, the data from fractionation and GPC confirmed the efficiency of using the sequential industrial solvents, including ethyl acetate, ethanol, methanol, and acetone. The GPC showed that the light compounds come out first with ethyl acetate following by heavy compounds with the next solvents. GPC data allow us to decide the way to separate the mixture of lignin for further experiment. Moreover, GPC data and fractionation indicate that acetone's final extraction is not necessary due to the low yield of this fraction and similar GPC profile with the solid via methanol extraction. Perhaps the performance of acetone is quite similar to methanol. In short, the fractionation of lignin with the sequential industrial solvents can separate lignin into different molecular weight parts and tailor the fraction of lignin for further conversion. The well-extraction of heavy compounds using methanol and acetone suggests that these solvents may be applied for the conversion of lignin, such as in the catalytic conversion of lignin.

\section{CONCLUSIONS}

We can conclude that the soda process of transforming woodchips into lignin is successful. The sequential industrial solvents fractionated lignin into different molecular weight fractions from light and 

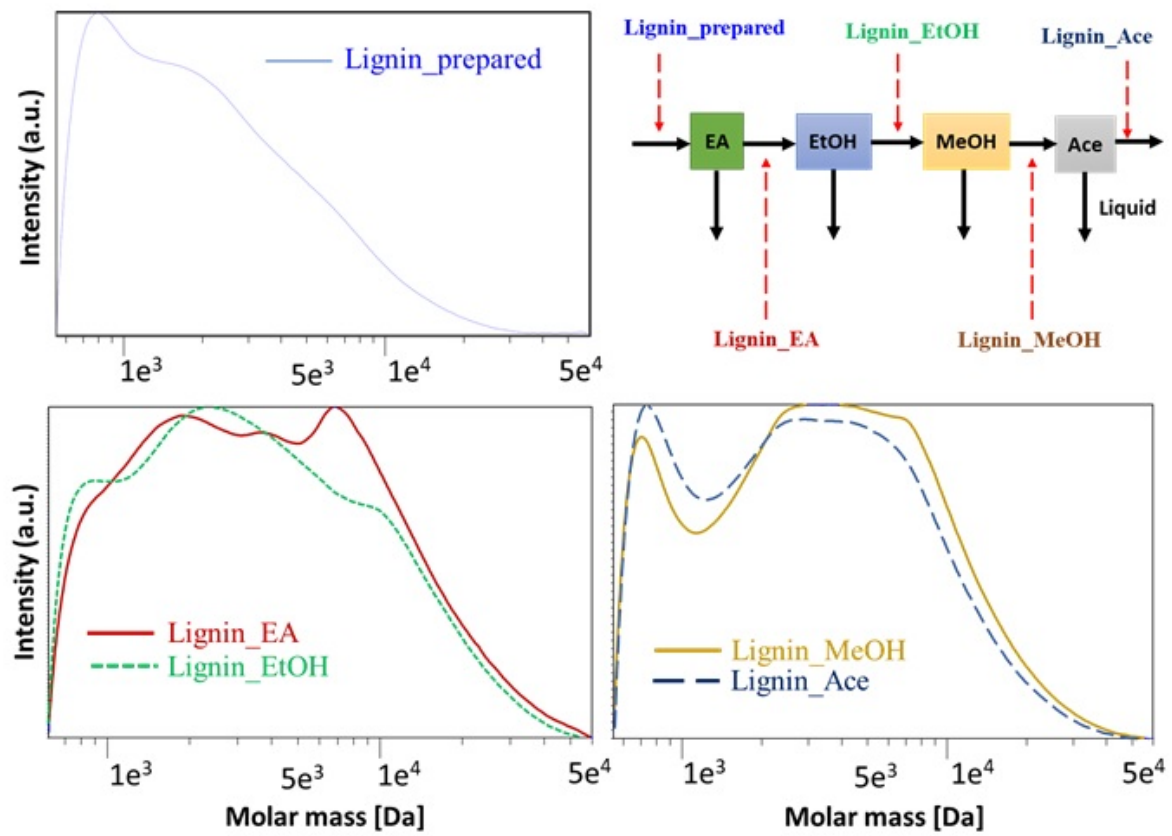

Figure 5: GPC curves of the prepared lignin and solid fractions after fractionating using the sequential industrial organic solvents of ethyl acetate, ethanol, methanol and acetone.

medium to heavy compounds confirmed by GPC data. The fractionation using organic solvents is necessary to separate the mixture of complex compounds into different small fractions, which are easy to convert into desired products.

\section{LIST OF ABBREVIATIONS}

Ace: Acetone

ATR: Attenuated total reflectance

DMSO: Dimethyl sulfoxide

EA: Ethyl acetate

EtOH: Ethanol

FT-IR: Fourier-transform infrared spectroscopy

GPC: Gel permeation chromatography

MeOH: Methanol

RID: Refractive index detector

\section{COMPETING INTERESTS}

The author(s) declare that they have no competing interests.

\section{ACKNOWLEDGMENT}

This research is funded by Vietnam National Foundation for Science and Technology Development (NAFOSTED) under grant number 104.05-2019.39.

\section{REFERENCES}

1. Patil PT, Armbruster U, Richter M, Martin A. Heterogeneously Catalyzed Hydroprocessing of Organosolv Lignin in Sub- and Supercritical Solvents. Energy Fuels. 2011;25(10):4713-4722. Available from: https://doi.org/10.1021/ef2009875.

2. Horáček J, Homola F, Kubičková I, Kubička D. Lignin to liquids over sulfided catalysts. Catal Today. 2012;179(1):191-198. Available from: https://doi.org/10.1016/j.cattod.2011.06.031.

3. Duval A, Vilaplana F, Crestini C, Lawoko M. Solvent screening for the fractionation of industrial kraft lignin. Holzforschung 2015;70(1):11-20. Available from: https://doi.org/10.1515/hf2014-0346.

4. Hu J, Zhang Q, Lee D-J. Kraft lignin biorefinery: A perspective. Bioresour Technol. 2018;247:1181-1183. PMID: 28899675. Available from: https://doi.org/10.1016/j.biortech.2017.08.169.

5. Sathawong S, Sridach W, Techato K. Lignin: Isolation and preparing the lignin based hydrogel. J Environ Chem Eng. 2018;6(5):5879-5888. Available from: https://doi.org/10.1016/ j.jece.2018.05.008.

6. Zhao Y, Deng L, Liao B, Fu Y, Guo QX. Aromatics production via catalytic pyrolysis of pyrolytic lignins from bio-oil. Energy Fuels. 2010;24(10):5735-5740. Available from: https://doi.org/ 10.1021/ef100896q.

7. Phung TK, Nguyen Q-TS, Vu KB, Duy-Le Vo G, Nguyen VN. Potential applications of waste lignin from the paper and pulp industry in Viet Nam. Sci Technol Dev J. 2020;23(4):716-726. Available from: https://doi.org/10.32508/stdj.v23i4.2442.

8. Glasser WG. About Making Lignin Great Again-Some Lessons From the Past. Front Chem. 2019;7(565). PMID: 31555636. Available from: https://doi.org/10.3389/fchem.2019.00565.

9. Lu Y, Lu Y-C, Hu H-Q, Xie F-J, Wei X-Y, Fan X. Structural Characterization of Lignin and Its Degradation Products with Spectroscopic Methods. J Spectrosc. 2017;2017:8951658. Available from: https://doi.org/10.1155/2017/8951658.

10. Berlin A, Balakshin M. Chapter 18 - Industrial Lignins: Analysis, Properties, and Applications. In: Gupta VK, Tuohy MG, 
Kubicek CP, Saddler J, Xu F, editors. Bioenergy Research: Advances and Applications. Amsterdam: Elsevier. 2014;p. 315336. PMID: 25340264. Available from: https://doi.org/10.1016/ B978-0-444-59561-4.00018-8.

11. Laurichesse $\mathrm{S}$, Avérous L. Chemical modification of lignins: Towards biobased polymers. Progr polymer sci. 2014;39(7):1266-1290. Available from: https://doi.org/10.1016/j.progpolymsci.2013.11.004.

12. Bajwa DS, Pourhashem G, Ullah AH, Bajwa SG. A concise review of current lignin production, applications, products and their environmental impact. Ind Crop Prod. 2019;139:111526. Available from: https://doi.org/10.1016/j.indcrop.2019.111526.

13. Lee $\mathrm{S}-\mathrm{H}$, Teramoto $\mathrm{Y}$, Shiraishi N. Resol-type phenolic resin from liquefied phenolated wood and its application to phenolic foam. J Appl Polym Sci. 2002;84(3):468-472. Available from: https://doi.org/10.1002/app.10018.

14. Lora JH, Glasser WG. Recent Industrial Applications of Lignin: A Sustainable Alternative to Nonrenewable Materials. J Polym Environ. 2002;10(1):39-48. Available from: https://doi.org/10. 1023/A:1021070006895.

15. Anderson EM, Katahira R, Reed M, Resch MG, Karp EM, Beckham GT, et al. Reductive Catalytic Fractionation of Corn Stover Lignin. ACS Sustain Chem Eng. 2016;4(12):6940-6950. Available from: https://doi.org/10.1021/acssuschemeng.6b01858.

16. Bosch S, Schutyser W, Koelewijn SF, Renders T, Courtin CM, Sels $\mathrm{BF}$. Tuning the lignin oil $\mathrm{OH}$-content with $\mathrm{Ru}$ and $\mathrm{Pd}$ catalysts during lignin hydrogenolysis on birch wood. Chem Commun. 2015;51(67):13158-13161. PMID: 26086373. Available from: https://doi.org/10.1039/C5CC04025F.

17. Zhang J, Teo J, Chen X, Asakura H, Tanaka T, Teramura $\mathrm{K}$ et al. A Series of $\mathrm{NiM}(\mathrm{M}=\mathrm{Ru}, \mathrm{Rh}$, and Pd) Bimetallic Catalysts for Effective Lignin Hydrogenolysis in Water. ACS Catal. 2014;4(5):1574-1583. Available from: https://doi.org/10.1021/ cs401199f.

18. Hossain MA, Phung TK, Rahaman MS, Tulaphol S, Jasinski JB, Sathitsuksanoh N. Catalytic cleavage of the $\beta$-O- 4 aryl ether bonds of lignin model compounds by $\mathrm{Ru} / \mathrm{C}$ catalyst. Appl Catal A. 2019;582:117100. Available from: https://doi.org/10. 1016/j.apcata.2019.05.034

19. Kuznetsov BN, Sharypov VI, Baryshnikov SV, Miroshnikova AV, Taran OP, Yakovlev VA, et al. Catalytic hydrogenolysis of native and organosolv lignins of aspen wood to liquid products in supercritical ethanol medium. Catal Today. 2020;Available from: https://doi.org/10.1016/j.cattod.2020.05.048.

20. Yang T, Wu K, Li B, Du C, Wang J, Li R. Conversion of lignin into phenolic-rich oil by two-step liquefaction in sub-supercritical ethanol system assisted by carbon dioxide. J Energy Inst. 2021;94:329-336. Available from: https://doi.org/10.1016/j. joei.2020.10.001.

21. Ren $T$, You S, Zhang M, Wang Y, Qi W, Su R, et al. Improved conversion efficiency of Lignin-to-Fuel conversion by limiting catalyst deactivation. Chem Eng J. 2021;410:128270. Available from: https://doi.org/10.1016/j.cej.2020.128270.

22. Chen S, Cheng H, Wu S. Pyrolysis characteristics and volatiles formation rule of organic solvent fractionized kraft lignin. Fuel. 2020;270:117520. Available from: https://doi.org/10. 1016/j.fuel.2020.117520.

23. Ajao O, Jeaidi J, Benali M, Abdelaziz OY, Hulteberg CP. Green solvents-based fractionation process for kraft lignin with controlled dispersity and molecular weight. Bioresour Technol. 2019;291:121799. PMID: 31351375. Available from: https: //doi.org/10.1016/j.biortech.2019.121799.

24. Araújo LCP, Yamaji FM, Lima VH, Botaro VR. Kraft lignin fractionation by organic solvents: Correlation between molar mass and higher heating value. Bioresour Technol. 2020;314:123757. PMID: 32645572. Available from: https: //doi.org/10.1016/j.biortech.2020.123757.

25. Domínguez-Robles J, Tamminen T, Liitiä T, Peresin MS, Rodríguez A, Jääskeläinen A-S. Aqueous acetone fractionation of kraft, organosolv and soda lignins. Int J Biol Macromol. 2018;106:979-987. PMID: 28834702. Available from: https: //doi.org/10.1016/j.ijbiomac.2017.08.102.

26. Li M-F, Sun S-N, Xu F, Sun R-C. Sequential solvent fractionation of heterogeneous bamboo organosolv lignin for valueadded application. Sep Purif Technol. 2012;101:18-25. Available from: https://doi.org/10.1016/j.seppur.2012.09.013.

27. Morck R, Yoshida H, Kringstad KP. Fractionation of Kraft Lignin by Successive Extraction with Organic Solvents. I. Functional Groups, 13C-NMR-Spectra and Molecular Weight Distributions. Holzforschung. 1986;40:51-60.

28. Ropponen J, Räsänen L, Rovio S, Ohra-aho T, Liitiä T, Mikkonen $\mathrm{H}$, et al. Solvent extraction as a means of preparing homogeneous lignin fractions. Holzforschung. 2011;65(4):543-549. Available from: https://doi.org/10.1515/hf.2011.089.

29. Thring RW, Vanderlaan MN, Griffin SL. Fractionation Of Alcell ${ }^{\circ}$ Lignin By Sequential Solvent Extraction. J Wood Chem Technol. 1996;16(2):139-154. Available from: https://doi.org/10. 1080/02773819608545815.

30. Pas D, Hickson A, Donaldson L, Lloyd-Jones G, Tamminen $T$, Fernyhough $A$, et al. Characterization of fractionated lignins polymerized by fungal laccases. BioResources 2011;6(2):1105-1121. Available from: https://doi.org/10. 15376/biores.6.2.1105-1121.

31. Wu Y, Ji H, Ji X, Tian Z, Chen J. Fibrillating wood chips to facilitate high-valued lignin extraction and high titer ethanol production. Ind Crops Prod. 2020;146:112153. Available from: https://doi.org/10.1016/j.indcrop.2020.112153.

32. Dias RM, da Costa Lopes AM, Silvestre AJD, Coutinho JAP, da Costa MC. Uncovering the potentialities of protic ionic liquids based on alkanolammonium and carboxylate ions and their aqueous solutions as non-derivatizing solvents of Kraft lignin. Ind Crops Prod. 2020;143:111866. Available from: https://doi. org/10.1016/j.indcrop.2019.111866.

33. Tian G, Xu J, Fu Y, Guo Y, Wang Z, Li Q. High $\beta$-O-4 polymeric lignin and oligomeric phenols from flow-through fractionation of wheat straw using recyclable aqueous formic acid. Ind Crops Prod. 2019;131:142-150. Available from: https://doi. org/10.1016/j.indcrop.2019.01.048. 